\title{
Managing Information in the Case of Opinion Spamming
}

\author{
Liping $\mathrm{Ge}^{1(\bowtie)}$ and Stefan $\operatorname{Vo}^{2(\bowtie)}$ \\ 1 Leuphana University of Lüneburg, \\ Universitätsallee 1, 21335 Lüneburg, Germany \\ liping.ge@leuphana.de \\ 2 Institute of Information Systems, University of Hamburg, \\ Von-Melle-Park 5, 20146 Hamburg, Germany \\ stefan.voss@uni-hamburg.de
}

\begin{abstract}
The rapid innovation of information and communication technology (ICT) within the last decades has come along with the development of new opportunities and challenges, new business models, new systems, etc. Companies like Amazon, Google or Alibaba shape business functions and percolate our daily life. Business operations go hand in hand with new types of user experiences when buying goes different than just traditional ways. Often it is not only the buying behavior but also the way recommendations are perceived as they may be readily available. This relates to opinion mining and, unfortunately, opinion spamming. We survey the issue of opinion spamming and fake review detection and focus on both sides of fake review groups, i.e., how to detect such groups but also how to set up a group that might be undetected with current methods. As both directions go hand in hand we elaborate on learning in both directions with the aim to improve related methods.
\end{abstract}

Keywords: Opinion spamming $\cdot$ Digital innovation $\cdot$ Information management $\cdot$ Digital transformation

\section{Introduction}

Product reviews have become an important part of decision making especially for individuals but also for organizations and companies when making buying decisions. This also relates to reviews on services and alike. One of the major problems faced in this context refers to opinion spamming which includes especially the notion of writing fake reviews to promote (or demote) certain products. Opinion spamming can go along the lines of individuals trying to work as influencing bodies. Even more so, fake review groups have become a popular means of enhanced opinion spamming. That is, here we are concerned about spam detection in a collaborative setting as well as the question on how to discover fake review groups. 
Opinion spamming and opinion mining are closely related to the field of sentiment analysis. Sentiment analysis refers to extracting opinions and/or emotions from documents or just simple pieces of text. While sentiment analysis can be used to investigate diverse media such as audio, video or images, we are mainly focused on extracting sentiments from written texts.

To be more specific, recent challenges arising while conducting sentiment analysis incorporate those occurring within the area of detecting fake reviews and spam. Social media, online vendor websites and other websites generally contain fake entries, comments and reviews [38]. Although responsible companies advertise that they follow their responsibility by deleting purchased reviews, agencies such as the Fivestar Marketing AG continue to offer fake review services which they present as allegedly legal methods $[16,29]$. This phenomenon is known in academia and even to the public; see, e.g., [2,28]. Also word-of-mouth tells us that there are a wealth of fake review groups all around the world without yet being detected.

To act against such distortions of public opinion, there are different measures that can be applied. For instance, the author's reputation could be checked and duplicates should be identified [39]. In [20], we see a wealth of data types that can be used in detection techniques. Moreover, these authors provide a review in the area of detection of spam reviews as well as related spam detection methods and techniques.

In this paper, we survey - again - the issue of opinion spamming and especially fake review groups. Several questions are considered.

- One of the questions is related to languages, i.e., to which extent are websites under different language regimes revealing a different approach; see, e.g., [47] for the Chinese market.

- How much value is in a report?

- Are reviews authentic? [40]

- Another research question, may be not necessarily an opportune one, relates to how a fake review group has to be set up so that detection with existing algorithms is difficult. This question should not necessarily increase the number of fake reviews but allow researchers to investigate new algorithms and methods to account for these settings.

- If opinion spamming refers to providing wrong or false information in reviews to misguide consumers and influence product sales, we might not necessarily have a comprehensive view on the subject. This is due to the fact that information in fake reviews may even be correct. How to deal with correct reviews from fake reviewers? (This would even open up the issue of having mystery shoppers included in the ball game.)

Elaborating on the above questions and the methods at hand (see the above or below references), after some more comprehensive but yet selective literature review, we start by using some frequent item set mining method to find a set of candidate groups. Behavioral models may investigate possible collusion among fake reviewers. Though, if we define groups based on different settings and relationships we end up in something that may just be related to reviewed 
products. ${ }^{1}$ In literature attempts are seen that successfully label fake review groups. Therefore, in our research we investigate both sides. On one hand we describe different approaches and models to set up fake review groups. On the other hand we apply available methods to see to which extent these groups may be discovered. This includes the extension of item sets as well as the specific "training" of related methods to find or not find what we have set. We conclude with managerial implications for both sides, i.e., the way of setting up those groups as well as the definition of methods aimed at detecting them. We end up - on a meta-level - with some critical reflection upon such research efforts, food for thought.

\section{Opinion Spamming Issues and Literature Review}

Generally, information may be viewed as purpose-oriented knowledge, demonstrating their use under various conditions and developments in reality to let decision makers take some actions; action-determined knowledge might be a similar focus. We define information management as purpose-oriented provision, processing, and distribution of the resource information for decision support as well as the provision of respective infrastructure [45]. That is, information management is understood, among others, as an instrument for making information distribution operable for an enterprise as well as for decision makers. In that respect it becomes an enabler for efficient business operations. Though, information management also has to enable decision makers to distinguish between different types of information when taking decisions: objective information (that would be needed), subjective information (a decision maker might think is needed), available information (including misleading or wrong information like fake information). Moreover, one might distinguish regarding the ease or difficulty of being able to reach some information. With that opinion spamming might be seen as part of information management.

In the spirit as mentioned in the introduction, papers stressing the reasoning for the advent of fake reviews seem to be a dime a dozen. Often, we also see connections to different words having the same or slightly different meaning, like deception theory, in the sense that reviews influence in the same way as information management tells us, e.g., that 'one cannot not communicate,' among others; see, e.g., [45] and some references therein. But, no matter where we consult the topic, fake reviews and opinion spamming are meant to increase the popularity (and at the end the revenues of related companies) of products, services, etc. Online reviews, influencers and alike are becoming more and more popular. Companies often use that kind of attention to post (or let others do so) reviews in favor of their own products and services or against those of other companies.

Spamming can be done by individuals [28] or by groups, where a coordination effort can be undertaken or not, i.e., individuals are possibly working together

\footnotetext{
${ }^{1}$ Just consider a fictitious person in some country setting up a fake review company using classmates abroad with diverse groups of friends and relations.
} 
without explicitly knowing. Individuals can be on hire or just sellers of one or more products promoting themselves and their products or services. In case of groups there may be coordinated efforts regarding people spamming while they have a homogenous or even a diverse background.

Next, we provide pointers to survey papers in the area, refer to the discussion of related issues on a meta-level and also mention some legal issues. Moreover, we provide references specifically dealing with fake review groups.

\subsection{Survey Papers}

Opinion spamming can be seen as a subfield of sentiment analysis. In sentiment analysis one studies phenomena along the extraction of opinions and/or emotions from documents like text, among others. Surveys on sentiment analysis seem to be a dime a dozen; for some recent examples see, e.g., [19,25,27,39,51]. Reviews/surveys focusing on opinion spamming and the detection of fake reviews include $[8,20,23,40]$.

An interesting observation, even if we might over-exaggerate a little, is that this area seems to have a larger proportion of surveys and reviews over original research papers than other areas (see also [27]).

An example for a recent and more or less comprehensive survey is [23]. They boil their search down to some 76 relevant papers or studies within a dozen years from 2007-2018 written in English. While we do not doubt the good intentions of the authors in finding some good references and conclusions, a considerable number of papers cited in our paper is not cited in theirs', though their search string should have found them. Moreover, if we understood their settings correctly, even their own paper would not have been found assuming the time horizon was extended to 2019. This could happen, e.g., if the searched databases for the study and the publication outlet for the study are not coinciding.

\section{$2.2 \quad$ Meta-Level and the Value of Reviews}

Opinion spamming is also observed on a meta-level. This means that we are not necessarily interested in individual reviews and their impact but more on generic issues regarding reviewing or evaluating in general. Among others, this relates to the knowledge of the public to which extent reviews could be manipulated. While even newspapers and magazines report about this in an ongoing manner $[16,28,29]$, the comprehension still seems quite different in different settings. For instance, in [2] it is argued whether it pays for a company to inform the public about the (possible) existence of fake reviews. For a well-established brand this may be beneficial while new kids on the block might be better off to let independent sources (like the mentioned newspapers) report on this. Using more or less bad prejudice, our interpretation of that and related studies is that havenots are get-nots ('if you are born poor you will stay poor').

From an academic standpoint discussions on the meta-level can often be found in marketing as well as information systems outlets. As an example see the journal where papers like [2] have appeared. 
Different social media platforms are building the foundation of reviews and opinion mining. This does not only concern the internet but also media like Twitter or Instagram. Especially on the latter platforms, we see some means of influencer marketing involving endorsements and product placement from people and/or organizations who have a purported level of social influence in their field. An influencer may provide testimonial advertising or play the role of a potential user or buyer. Their actions and behavior may be more subtle than that of professionals like journalists, academics or industry analysts.

Let us first exemplify regarding the use of Twitter and alike for opinion mining. Subjective user opinions of mobility networks can be used to judge upon the satisfaction level of users of mass transit systems, especially in the case of disturbances $[18,26]$. Based on these social media platforms it is possible to design a system architecture allowing to automatically capture the user comprehension and perspective based on sentiment analysis of the user-generated content. Being aware of data security issues, users or customers may be used or exploited as sensors of mobility dynamics (in a sense contributing towards the building of heatmaps), indicating where and how disturbances are observed within the public transport network. Nowcasting or microblogging from messages posted on Twitter provides real-time sensing of traffic-related information.

[35] study the motivations behind incentivized consumer reviews generated via influencer marketing campaigns.

Some of the issues related to opinion mining and opinion spamming concern the implications that reviews may have not only towards other users or potential customers but also as a feedback mechanism towards the company itself. Once analyzed in detail, reviews, whether they are fake reviews or real ones, may help to improve or advance services and products. That is, suggestions, tips and advice, which are often explicitly sought and needed by both brand owners and consumers may be seen as suggestions and the related task of mining suggestions from opinionated text on social media may be termed suggestion mining [32]. Once interpreted in a slightly different way, this may also be viewed as crowdsourcing; see, e.g., [30]. This connection to crowdsourcing and the possibility of disintermediation between customers and companies is also exemplified in [44].

Let us take a different domain as an example: Writing nice book reviews can be an art and still they may be fake reviews. Consider, e.g., the phrase "This book has a solid cover; so far for its advantages." Actually this need not be a fake review and even the issue whether the sentiment can be discovered as negative might not be clear in all cases. Based on this, let us turn towards the following question: How much value is in a report?

Considering book reviews, we may consult [7] as they refer to the characteristic of a product or a service being hedonic, including books (while our example in the Appendix, Fig. 1, might not be what they mean). Hedonic aspects of products are even more difficult to evaluate than technical ones. In this case, opinion leaders, such as critics, may serve as key informants to consumers (later we may also come to the case of mystery shoppers who are somewhat different). The study of [7] considers the different roles and incentives of literary critics 
and how they influence the success of books. Similar issues actually also hold for movies. Both involve multisensory, fantasy, emotive aspects and relate to symbolic motives. Moreover, the diffusion patterns of these products are also different than technical ones. Nevertheless, fake reviews may be an issue, too. Extending the above-mentioned issues, [42] provide elasticities as standardized measures for the relationships between the success of different types of products like movies or video games and critics' volume, average, positive and negative valence, and the variation in critics' appeal; like other issues in this paper, food for thought.

Without going too much into detail, language might have a major impact regarding opinion spamming as there may be native speakers publishing in their own language, non-native speakers publishing in other languages than their mother tongue. While most of the companies that we may look at, are using multiple language environments, this need not be true in general. An interesting issue is to which extent this influences the behavior of opinion spammers and their possible detection.

For examples considering the issues in different languages see, e.g., [36] (Russian) and [47] (Chinese).

\subsection{Legal Issues}

Fake reviews may be judged differently throughout the world according to different legal policies and laws. That is, often spamming may become a legal issue and the question arises to which extent lawmakers have done a good job to set up an environment where lawbreakers may be prosecuted; see, e.g., [22] for an Australian investigation. A comprehensive consideration with a focus on US law is given by [44]. The overall question, though, refers to the fact that lawmakers still seem to have considerable difficulties to set the pace on an international transboundary level.

Recently, to give some specific example, the German Bundesgerichtshof decided a specific case (regarding Yelp) such that reputation software may be used to filter reviews [4]. The problem that seems inherent is that the quality of the software and its algorithms is nontransparent.

Touching the information management issue is done in [34].

\subsection{Literature on Fake Review Groups}

When opinion mining aims to summarize the amount of appreciation and criticism in a given text, this may be done favorably also or especially in a collaborative effort, i.e., using fake review groups. Fake review groups relate to opinion spamming in a collaborative effort. There are quite a few sources available studying spam detection in this setting including $[6,31,48,49]$.

Considering fake review groups means forming (eventually artificial) communities that are working together to increase the possible influence of their opinions. Analyzing community structures built through abnormal non-random 
positive interactions is done, e.g., by [6]. On the one hand one has fake reviewers who eventually post spam reviews and/or support comments of others, especially fellow group members. Through extensive experimental analysis, [6] show the impact of a community-based approach in terms of accuracy and reliability. They show that their approach can successfully identify spam reviews without relying on review content, while achieving the same level of accuracy as stateof-the-art pure content-based classifiers. Once calling the same or similar issues as coming from deception theory we may refer to, e.g., [50].

We should note that the issue of fake reviews may be different in different settings (while we have not yet put any evidence on related commonalities and differences). Table 1 in the appendix provides examples with comments and references regarding various related events observed over time.

\section{Methods}

Various algorithms are available, mostly coming from areas such as machine learning, statistics and operations research. Besides describing the methods themselves, one also needs to think about possible datasets.

\subsection{A Sketch of Available Methods}

The above mentioned survey papers also include a comprehensive list of references regarding available methods. In the sequel, we first summarize a few pointers and then sketch a limited number of available methods.

- Binomial regression: [41]

- Latent Dirichlet Allocation (LDA): [11]

An example for a comparative implementation of different supervised techniques such as Support Vector Machine (SVM), Multinomial Naive Bayes (MNB), and Multilayer Perceptron can be found in [21]. The presented results indicate that all the mentioned supervised techniques can successfully detect fake reviews with more than $86 \%$ accuracy.

In [11] an unsupervised topic-sentiment joint probabilistic model based on an LDA model is proposed. To be more specific, the automatic identification of topics to describe the distribution of words within a considered cluster is related to LDA. LDA is a generative probabilistic model proposed by [3], which has been successfully used to identify latent topics within corpora. In a nutshell, LDA assumes that documents in a corpus are represented as random mixtures over latent topics and, in turn, each topic is characterized by a distribution over a set of words. For each document in a corpus, the generative process of the words included in that document works as follows: (i) Select a topic from a multinomial distribution, and (ii) select a word from that topic. Thus, LDA is about estimating two probability matrices, i.e., a document-topic matrix, giving the probability that a certain document contains a latent topic, and a topic-word 
matrix, modeling the probability that a latent topic uses a certain word. For an in-depth presentation of LDA, along with its application to topic modeling, document classification, and collaborative filtering we direct the interested reader to $[3]$.

Further references include the following. In [52], an interesting approach is followed regarding spam detection. While this is not the same as fake review detection, the approach itself is worth being considered. Actually, as a starting point, the authors use a wrapper-based feature selection method to extract crucial features. Second, a decision tree is chosen as the classifier model with a well-known training approach. Actually, particle swarm optimization (PSO) is used to solve the related problem. In [10] the geolocation features of shops are included.

\subsection{Datasets}

The survey of [23] lists a table with some ten references with various datasets used by the cited authors, including those from Amazon, Datatang, Resellerratings and TripAdvisor. The number of reviewers goes from a couple of hundreds towards a bit more than a million where multiple reviews by the reviewers have been performed in some up to many cases.

Datasets used in [21] are mimicking cases from Amazon and TripAdvisor. Amazon Mechanical Turk can also be used to generate datasets; see [33] for an example to do so.

\section{Conclusions}

In this paper we have looked at opinion spamming based on selected literatures. Implicitly an information management approach gave us a slightly different edge over existing reviews. In passing, we have seen quite a few issues that are worth being explored further. In that sense we can see the value of this paper as one initializing further research. Let us distinguish between some food for thought and some explicit future research directions.

\subsection{Lessons Learned and Food for Thought}

One of the questions not comprehensively answered in current research relates to what a fake review is or can be and who is responsible for it. Let us provide a recent example from a platform like Ebay or Amazon. Let us assume that we bought some item (say, a face mask) from some vendor for a certain price and we provided a good review (say good value for money given the paid price). Based on the current situation (early 2020 with the spread of the corona virus) the price was multiplied by a factor of, say, about five to six or even more. Now our review is still in the system but the basic notion of good value for money has turned and we would have dared to give any star if we would have known or 
paid the current price. That is, the vendor made our review and those of fellow reviewers a fake review. How is this detected?

In the area of public transport where we are dealing with the provision of services as a product, we have seen the use of Twitter etc. for traffic-related comments (see Sect.2.2). These are reviews, too; they are or may be opinionate and one might learn how to set up an environment where fake reviews are not so frequent.

Academic papers are supposed to be 'peer-'reviewed, too. Though, also that system may be flawed and one might have to think on how to cope with that $[9,13]$.

\subsection{Future Research}

Future research should enhance different views on fake reviews. Interesting observations could be done by mystery shoppers. Mystery shopping is a form of participant observation, which uses especially trained persons to perform the tasks of buyers to let personnel believe that they are serving real customers or real potential customers. For an entry point to mystery shoppers we refer to, e.g., $[24,46]$. For specific applications in the above mentioned public transport context see, e.g., $[15,43]$.

While a mystery shopper might not have the same computing capability standing behind an automatic evaluation of reviews, he/she might be able to judge upon statements and judgements based on real experience. Based on that experience mirrored with automatic evaluations, a different kind of training approach might be observed worth being explored as future research. If this is seen in the light of algorithm development, we might actually see advanced methods for fake review detection.

\section{Appendix}

In this appendix we provide a hands-on set of arguments why fake reviews might be an issue; see, e.g., $[12,17]$. Moreover, we survey quite a few companies and settings in which fake reviews may have some major impact; see Table 1.

Let us exemplify possible reasons for fake reviews. First of all, there are many advisors trying to support businesses in selling on online platforms. And, secondly, there is their advise. As a producer one provides detailed product descriptions, high-quality images and videos, competitive pricing and possibly some customer service. Once this has been set up and one tries to be sold through an e-commerce or online platform, there are eventually recommendations of the system, rankings and alike. If one does not make it to the 'first' page, one might be overseen. Customers might use some sorting and check for one or two pages, not more, do they? Therefore, an online seller might have to understand how a product ranking works (and of course the specificity of the request might do the job, too). There are actually two types to consider. 


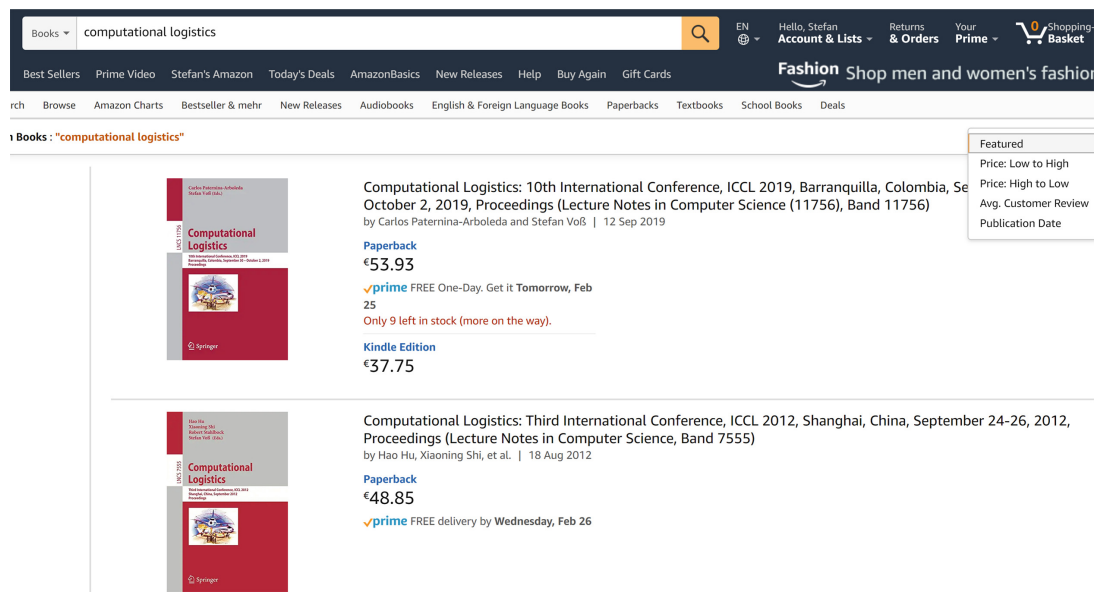

Fig. 1. Searching on Amazon; example

- Traditional Search Rank. This is where your product appears when someone does a search for a related keyword; this is related to common search engines.

- The Buy Box. This is where Amazon differs from many others. The buy box is a box that can be found on the product page that customers click on to an item to their shopping cart (see especially the upper part and the right hand upper corner of Fig. 1). When multiple sellers offer the same item, one has to compete to appear there.

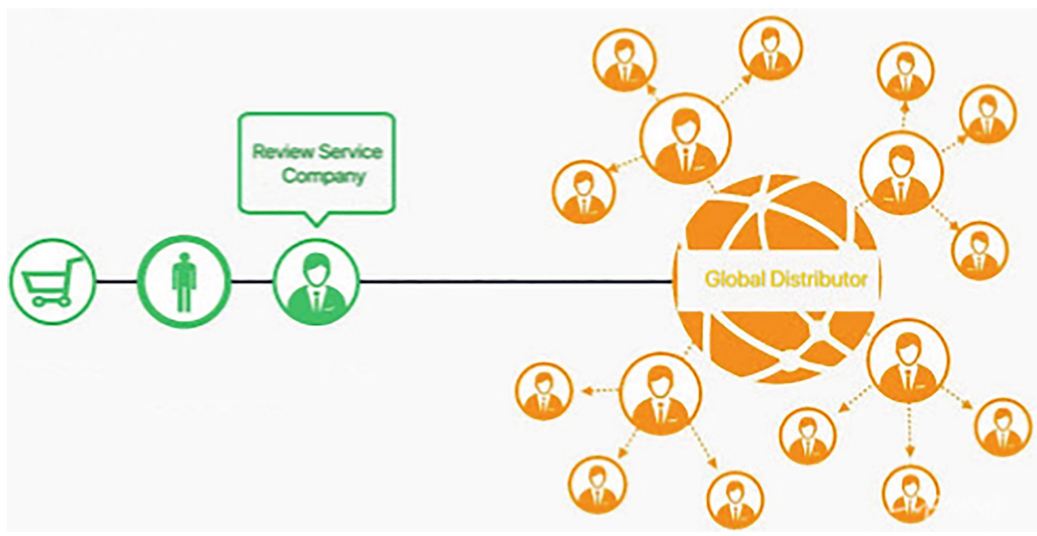

Fig. 2. Settings of fake review groups.

Advise goes on in claiming that sellers should price their items competitively, maintain a positive selling history, increase sales and provide thorough 
Table 1. Companies and webpages, study objects

\begin{tabular}{|c|c|c|c|}
\hline Company/webpage & Area specifications & Comments & $\begin{array}{l}\text { (Selected) } \\
\text { references }\end{array}$ \\
\hline Alibaba.com & $\begin{array}{l}\text { E-commerce platform (main } \\
\text { focus on business-to-business) }\end{array}$ & $\begin{array}{l}\text { Alexpress.com as an online } \\
\text { shopping company belongs to } \\
\text { Alibaba }\end{array}$ & {$[5]$} \\
\hline Amazon.com & $\begin{array}{l}\text { Technology company focusing } \\
\text { on e-commerce, cloud } \\
\text { computing etc. }\end{array}$ & $\begin{array}{l}\text { Listed on Nasdaq. Many data } \\
\text { sets for further study and } \\
\text { comparison can be found on } \\
\text { the web }\end{array}$ & $\begin{array}{l}\text { [1], for data sets } \\
\text { see, e.g., [6] }\end{array}$ \\
\hline Booking.com & Lodging & $\begin{array}{l}\text { Companies like Booking.com } \\
\text { have decreased the } \\
\text { possibilities for fake reviews } \\
\text { by allowing only actual users } \\
\text { of their reservation system } \\
\text { who have booked and stayed } \\
\text { in a particular hotel to write } \\
\text { a review about it }\end{array}$ & \\
\hline Google.com & Web search engine & $\begin{array}{l}\text { The company also includes } \\
\text { Google Play and many others }\end{array}$ & {$[37]$} \\
\hline Taobao.com & $\begin{array}{l}\text { E-commerce platform (main } \\
\text { focus on } \\
\text { consumer-to-consumer) }\end{array}$ & & \\
\hline TripAdvisor.com & $\begin{array}{l}\text { Transportation, lodging, } \\
\text { travel experiences, and } \\
\text { restaurants }\end{array}$ & $\begin{array}{l}\text { Listed on the Nasdaq, } \\
\text { includes Expedia etc. }\end{array}$ & {$[14,22]$} \\
\hline Yelp.com & $\begin{array}{l}\text { Business directory service } \\
\text { and crowdsourced review } \\
\text { forum }\end{array}$ & $\begin{array}{l}\text { Traded at NYSE. } \\
\text { Occasionally, journalists say } \\
\text { "to yelp" when they mean } \\
\text { "to write an online review" }\end{array}$ & {$[4]$} \\
\hline
\end{tabular}

product information. Actually, maintaining a positive selling history includes as a tip to actively seek (positive) reviews. Moreover, it is claimed that buying fake reviews is an offence, but the way it is done, it makes the issue an interesting one in any dimension. That is, based on the importance of reviews and the traditional literature review defecting model, now many reviewers have become more advanced. Together with the sellers and an intermediate service company, they possibly build up (more or less large) communication groups using well-known social media like Facebook, Whats'app, Wechat etc. and continue to involve new members to anti-fake reviewer defection, trying to hide themselves deeply and pretend to be real reviewers. If one searches for review groups on Facebook, one actually can find many of them. Units can be country-oriented with the most prominent examples found in Germany, the USA and China. The group focuses on involving more and more new reviewers, closely related to a snowball system. Based on the different historical development with established and new users, reviews are more likely accepted by any review detection system. The classical idea is that each fake reviewer gets free products eventually supplemented by a commission (say, within 5-30 US\$, depending on the value of the product and the urgency of reviews needed). Moreover, the commission fee may be different depending on whether, e.g., photos or videos are included. In a sense, fake reviewer groups have developed a 3-layer distribution system (see Fig. 2). 


\section{References}

1. Ata-Ur-Rehman, et al.: Intelligent interface for fake product review monitoring and removal. In: 16th International Conference on Electrical Engineering, Computing Science and Automatic Control (CCE), pp. 1-6 (2019). https://doi.org/10.1109/ ICEEE.2019.8884529

2. Bambauer-Sachse, S., Mangold, S.: Do consumers still believe what is said in online product reviews? A persuasion knowledge approach. J. Retail. Consum. Serv. 20(4), 373-381 (2013). https://doi.org/10.1016/j.jretconser.2013.03.004

3. Blei, D., Ng, A., Jordan, M.: Latent Dirichlet allocation. J. Mach. Learn. Res. 3, 993-1022 (2003). http://www.jmlr.org/papers/v3/blei03a. Accessed 24 Feb 2020

4. Bundesgerichtshof: Zur Zulässigkeit der Bewertungsdarstellung von Unternehmen auf einem Internet-Bewertungsportal (www.yelp.de) (2020). https://www. bundesgerichtshof.de/SharedDocs/Pressemitteilungen/DE/2020/2020007.html. Accessed 24 Feb 2020

5. Chengzhang, J., Kang, D.: Detecting spamming stores by analyzing their suspicious behaviors. In: 17th International Conference on Advanced Communication Technology (ICACT), pp. 502-507 (2015). https://doi.org/10.1109/ICACT.2015. 7224845

6. Choo, E., Yu, T., Chi, M.: Detecting opinion spammer groups through community discovery and sentiment analysis. In: Samarati, P. (ed.) DBSec 2015. LNCS, vol. 9149, pp. 170-187. Springer, Cham (2015). https://doi.org/10.1007/978-3-31920810-7_11

7. Clement, M., Proppe, D., Rott, A.: Do critics make bestsellers? Opinion leaders and the success of books. J. Med. Econ. 20(2), 77-105 (2007). https://doi.org/10. $1080 / 08997760701193720$

8. Crawford, M., Khoshgoftaar, T.M., Prusa, J.D., Richter, A.N., Najada, H.A.: Survey of review spam detection using machine learning techniques. J. Big Data 2 (2015). Article no 23. https://doi.org/10.1186/s40537-015-0029-9

9. Cyranoski, D.: China cracks down on fake peer reviews. Nature 546(7659) (2017). https://doi.org/10.1038/546464a

10. Deng, R., et al.: SpamTracer: manual fake review detection for O2O commercial platforms by using geolocation features. In: Guo, F., Huang, X., Yung, M. (eds.) Inscrypt 2018. LNCS, vol. 11449, pp. 384-403. Springer, Cham (2019). https:// doi.org/10.1007/978-3-030-14234-6_21

11. Dong, L.Y., et al.: An unsupervised topic-sentiment joint probabilistic model for detecting deceptive reviews. Expert Syst. Appl. 114, 210-223 (2018). https://doi. org/10.1016/j.eswa.2018.07.005

12. Dunne, C.: 5 ways to help you generate genuine Amazon reviews (2020). https://www.feedbackexpress.com/the-how-tos-for-amazon-reviews/. Accessed 24 Feb 2020

13. Faria, J., Goel, R.: Returns to networking in Academia. Netnomics 11, 103-117 (2010). https://doi.org/10.1007/s11066-010-9048-z

14. Fenton, S.: TripAdvisor denies rating system is flawed, after fake restaurant tops rankings in Italy. The Independent (2015). https://www.independent.co.uk/lifestyle/gadgets-and-tech/news/tripadvisor-denies-rating-system-is-flawed-afterfake-restaurant-tops-rankings-in-italy-10354818.html. Accessed 24 Feb 2020

15. Georgiadis, G., Xenidis, Y., Toskas, I., Papaioannou, P.: A performance measurement system for public transport services in Thessaloniki, Greece. In: Transport Research Arena (TRA) 5th Conference: Transport Solutions from Research to Deployment, Paris (2014) 
16. Gierow, H.: Amazon löscht eine halbe Million gekaufter Bewertungen (2016). https://www.golem.de/news/online-shopping-amazon-loescht-eine-halbemillion-gekaufter-bewertungen-1611-124718.html

17. Grosman, L.: Five tips to improve your ranking on Amazon (2017). https://www. forbes.com/sites/forbescommunicationscouncil/2017/02/28/five-tips-to-improveyour-ranking-on-amazon/\#33f6707e9fed. Accessed 24 Feb 2020

18. Haghighi, N., Liu, X., Wei, R., Li, W., Shao, H.: Using Twitter data for transit performance assessment: a framework for evaluating transit riders' opinions about quality of service. Public Transp. 10, 363-377 (2018). https://doi.org/10.1007/ s12469-018-0184-4

19. Hemmatian, F., Sohrabi, M.: A survey on classification techniques for opinion mining and sentiment analysis. Artif. Intell. Rev. 52(3), 1495-1545 (2019). https:// doi.org/10.1007/s10462-017-9599-6

20. Heydari, A., Tavakoli, M., Salim, N., Heydari, Z.: Detection of review spam: a survey. Expert Syst. Appl. 42(7), 3634-3642 (2015). https://doi.org/10.1016/j. eswa.2014.12.029

21. Hossain, M.F.: Fake review detection using data mining, Master thesis, Missouri State University (2019)

22. Hunt, K.M.: Gaming the system: fake online reviews v. consumer law. Comput. Law Secur. Rev. 31(1), 3-25 (2015). https://doi.org/10.1016/j.clsr.2014.11.003

23. Hussain, N., Turab Mirza, H., Rasool, G., Hussain, I., Kaleem, M.: Spam review detection techniques: a systematic literature review. Appl. Sci. 9(987), 1-26 (2019). https://doi.org/10.3390/app9050987

24. Jacob, S., Schiffino, N., Biard, B.: The mystery shopper: a tool to measure public service delivery? Int. Rev. Adm. Sci. 84(1), 164-184 (2018). https://doi.org/10. $1177 / 0020852315618018$

25. Kaur, H., Mangat, V., Nidhi: a survey of sentiment analysis techniques. In: 2017 International Conference on I-SMAC (IoT in Social, Mobile, Analytics and Cloud), pp. 921-925. IEEE (2017). https://doi.org/10.1109/I-SMAC.2017.8058315

26. Kokkinogenis, Z., Filguieras, J., Carvalho, S., Sarmento, L., Rossetti, R.J.: Mobility network evaluation in the user perspective: real-time sensing of traffic information in Twitter messages. In: Rossetti, R.J., Liu, R. (eds.) Advances in Artificial Transportation Systems and Simulation, pp. 219-234. Academic Press, Boston (2015). https://doi.org/10.1016/B978-0-12-397041-1.00012-1

27. Körner, T., Voß, S.: State-of-the-art and scientific contribution in the field of sentiment analysis. Technical report, IWI, University of Hamburg (2019)

28. Kühn, A.: Wie Schüler mit frisierten Bewertungen bei Amazon Geld verdienen und Käufer in die Irre führen. Spiegel 42/2019, 83 (2019)

29. Kwidzinski, R.: Diese Firma verkauft gute Bewertungen. Allgemeine Hotelund Gastronomie-Zeitung, 7 August (2017). https://www.ahgz.de/news/onlinemarketing-diese-firma-verkauft-bewertungen, 200012241347.html

30. Martin, N., Lessmann, S., Voß, S.: Crowdsourcing: Systematisierung praktischer Ausprägungen und verwandter Konzepte. In: Bichler, M., et al. (eds.) Multikonferenz Wirtschaftsinformatik 2008, pp. 1251-1263. Gito, Berlin (2008)

31. Mukherjee, A., Liu, B., Glance, N.: Spotting fake reviewer groups in consumer reviews. In: Proceedings of the 21st International Conference on World Wide Web, WWW 2012, pp. 191-200. ACM, New York (2012). https://doi.org/10.1145/ 2187836.2187863

32. Negi, S., Buitelaar, P.: Suggestion mining from opinionated text. In: Pozzi, F., Fersini, E., Messina, E., Liu, B. (eds.) Sentiment Analysis in Social Networks, pp. 
129-139. Morgan Kaufmann, Boston (2017). https://doi.org/10.1016/B978-0-12804412-4.00008-5

33. Ott, M., Cardie, C., Hancock, J.: Estimating the prevalence of deception in online review communities. In: Proceedings of the 21st International Conference on World Wide Web, pp. 201-210. ACM, New York (2012). https://doi.org/10. $1145 / 2187836.2187864$

34. Patterson, M.R.: Antitrust Law in the New Economy: Google, Yelp, LIBOR, and the Control of Information. Harvard University Press, Cambridge (2017)

35. Petrescu, M., O'Leary, K., Goldring, D., Ben Mrad, S.: Incentivized reviews: promising the moon for a few stars. J. Retail. Consum. Serv. 41, 288-295 (2018). https://doi.org/10.1016/j.jretconser.2017.04.005

36. Pisarevskaya, D., Litvinova, T., Litvinova, O.: Deception detection for the Russian language: lexical and syntactic parameters. In: Proceedings of Natural Language Processing and Information Retrieval Workshop, pp. 1-10, Varna, Bulgaria (2017). https://doi.org/10.26615/978-954-452-038-0_001

37. Rahman, M., Rahman, M., Carbunar, B., Chau, D.H.: Search rank fraud and malware detection in Google Play. IEEE Trans. Knowl. Data Eng. 29(6), 13291342 (2017). https://doi.org/10.1109/TKDE.2017.2667658

38. Rahmath, H.: Opinion mining and sentiment analysis - challenges and applications. Int. J. Appl. Innov. Eng. Manag. 3(5), 401-403 (2014). http://www.ijaiem.org/ volume3issue5/IJAIEM-2014-05-31-124.pdf

39. Rajalakshmi, S., Asha, S., Pazhaniraja, N.: A comprehensive survey on sentiment analysis. In: Fourth International Conference on Signal Processing, Communication and Networking (ICSCN), pp. 1-5. IEEE (2017). https://doi.org/10.1109/ICSCN. 2017.8085673

40. Rastogi, A., Mehrotra, M.: Opinion spam detection in online reviews. J. Inf. Knowl. Manag. 16(04, article \#1750036) (2017). https://doi.org/10.1142/ S0219649217500368

41. Savage, D., Zhang, X., Yu, X., Chou, P., Wang, Q.: Detection of opinion spam based on anomalous rating deviation. Expert Syst. Appl. 42(22), 8650-8657 (2015). https://doi.org/10.1016/j.eswa.2015.07.019

42. Schulz, P., Hofmann, J., Clement, M., Burmester, A.B.: The role of professional critics in product success - a meta-analysis. Technical report, University of Hamburg, Hamburg Business School (2019)

43. Sidorchuk, R., Efimova, D., Lopatinskaya, I., Kaderova, V.: Parametric approach to the assessment of service quality attributes of municipal passenger transport in Moscow. Mod. Appl. Sci. 9(4), 303-311 (2015). https://doi.org/10.5539/mas. v9n4p303

44. Tessuto, G., Bhatia, V.K., Garzone, G., Salvi, R., Williams, C. (eds.): Constructing Legal Discourses and Social Practices: Issues and Perspectives. Cambridge Scholars, Newcastle upon Tyne (2018)

45. Voß, S., Gutenschwager, K.: Informationsmanagement.. Springer, Berlin (2001). https://doi.org/10.1007/978-3-642-56878-7

46. Wilson, A.M.: Mystery shopping: using deception to measure service performance. Psychol. Market. 18(7), 721-734 (2001). https://doi.org/10.1002/mar.1027

47. Xu, C., Zhang, J., Chang, K., Long, C.: Uncovering collusive spammers in Chinese review websites. In: Proceedings of the 22nd ACM International Conference on Information \& Knowledge Management, pp. 979-988. ACM, New York (2013). https://doi.org/10.1145/2505515.2505700 
48. Xu, G., Hu, M., Ma, C., Daneshmand, M.: GSCPM: CPM-based group spamming detection in online product reviews. In: IEEE International Conference on Communications (ICC), pp. 1-6 (2019). https://doi.org/10.1109/ICC.2019.8761650

49. Ye, J., Akoglu, L.: Discovering opinion spammer groups by network footprints. In: Appice, A., Rodrigues, P.P., Santos Costa, V., Soares, C., Gama, J., Jorge, A. (eds.) ECML PKDD 2015. LNCS (LNAI), vol. 9284, pp. 267-282. Springer, Cham (2015). https://doi.org/10.1007/978-3-319-23528-8_17

50. Yoo, K.H., Gretzel, U.: Comparison of deceptive and truthful travel reviews. In: Information and Communication Technologies in Tourism, pp. 37-47, Vienna (2009). https://doi.org/10.1007/978-3-211-93971-0_4

51. Yousif, A., Niu, Z., Tarus, J., Ahmad, A.: A survey on sentiment analysis of scientific citations. Artif. Intell. Rev. 52(3), 1805-1838 (2019). https://doi.org/10. 1007/s10462-017-9597-8

52. Zhang, Y., Wang, S., Phillips, P., Ji, G.: Binary PSO with mutation operator for feature selection using decision tree applied to spam detection. Knowl.-Based Syst. 64, 22-31 (2014), https://doi.org/10.1016/j.knosys.2014.03.015 